\title{
From my laptop
}

A year of challenges and turbulence is finally coming to an end. Covid-19 is still here to stay and remains a significant part of our life. With the fear and anxiety of Covid-19, the wave of 'new normal' set in. The internet of things and everything virtual is now a big chunk of the new normal, including scientific conferences. The 10th Conjoint Ophthalmology Scientific Conference (COSC) 2020 turned virtual on 18-19 September 2021. This conference is a collaborative effort of Universiti Sains Malaysia, Universiti Malaya, Universiti Kebangsaan Malaysia, and Ministry of Health since 2011. The long history of COSC is available in the supplement accompanying this issue of the Malaysian Journal of Ophthalmology (MyJO). Do check out this interesting history!

MyJO marked another first with the publication of this supplement, which comprises abstracts accepted in the successful virtual 10th COSC. Kudos to Hospital Selayang team (Ministry of Health) for an informative, well organized, and interesting conference.

To all Malaysian ophthalmologists and the young trainees, please continue to work together toward the greater success of our fraternity in Malaysia and abroad. I wish you all a happy new year and a restful and well-deserved end of the year break. See you next year energized with new resolutions and new dreams. Let us dream for indexation of MyJO!

Till we meet again.

Professor Dr. Liza Sharmini Ahmad Tajudin Chief Editor 